\title{
Article \\ Characterization of Precipitation in 7055 Aluminum Alloy by Laser Ultrasonics
}

\author{
Zhenge Zhu ${ }^{1,2}$, Hao Peng ${ }^{1,2}$, Yacheng $X u^{1,2}$, Xueyong Song ${ }^{1,2}$, Jinrong Zuo ${ }^{1,2} \mathbb{D}$, Ying Wang ${ }^{1,2}$, Xuedao Shu ${ }^{1,2} \mathbb{D}$ \\ and Anmin Yin 1,2,* \\ 1 Department of Mechanical Engineering, School of Mechanical Engineering and Mechanics, \\ Ningbo University, Ningbo 315211, China; z739713297@163.com (Z.Z.); ph419533118@163.com (H.P.); \\ XYC15655312723@126.com (Y.X.); sxy18868641732@163.com (X.S.); zuojinrong@nbu.edu.cn (J.Z.); \\ wangying5@nbu.edu.cn (Y.W.); shuxuedao@nbu.edu.cn (X.S.) \\ 2 Zhejiang Key Laboratory of Parts Rolling Technology, School of Mechanical Engineering and Mechanics, \\ Ningbo University, Ningbo 315211, China \\ * Correspondence: yinanmin@nbu.edu.cn; Tel.: +86-0574-8760-0534
}

check for updates

Citation: Zhu, Z.; Peng, H.; Xu, Y.; Song, X.; Zuo, J.; Wang, Y.; Shu, X.; Yin, A. Characterization of Precipitation in 7055 Aluminum Alloy by Laser Ultrasonics. Metals 2021, 11, 275. https://doi.org/ 10.3390/met11020275

Academic Editors: Germán F. de la Fuente and Rajashekhara Shabadi Received: 11 November 2020

Accepted: 29 January 2021

Published: 5 February 2021

Publisher's Note: MDPI stays neutral with regard to jurisdictional claims in published maps and institutional affiliations.

Copyright: (c) 2021 by the authors. Licensee MDPI, Basel, Switzerland. This article is an open access article distributed under the terms and conditions of the Creative Commons Attribution (CC BY) license (https:/ / creativecommons.org/licenses/by/ $4.0 /)$.

\begin{abstract}
After different rolling conditions, four 7055 aluminum alloy samples with different precipitation sizes were measured by scanning electron microscope, transmission electron microscope and laser ultrasonic. The attenuation coefficients of ultrasound measured by laser ultrasonic were calculated in the time domain, frequency domain and wavelet denoising, respectively. The relationship between the precipitate size and attenuation coefficient was established. The results show that the attenuation of the ultrasonic wave is related to the size of the precipitated phase; this provides a new method for rapid non-destructive testing of the precipitation of aluminum alloys.
\end{abstract}

Keywords: precipitation; 7055 aluminum alloys; laser ultrasonic; wavelet threshold denoising

\section{Introduction}

Aluminum alloy has a series of advantages and is widely used [1,2]. The 7055 aluminum alloy is a new generation of high-strength $\mathrm{Al}-\mathrm{Zn}-\mathrm{Mg}-\mathrm{Cu}$ series aluminum alloy and is an ultra-high-strength aluminum alloy that can be heat-treated [3]. The 7055 aluminum alloy has advantages such as low density, high strength to weight ratio, good toughness, and high corrosion resistance, and thus is a major material for the aerospace industry [4].

In the typical age-hardened alloy systems, alloying elements may exist in the form of randomly distributed solute atoms in solid solution, or in the form of constituent elements of precipitates with specific crystal structures. It has been shown that the strength of aluminum alloy mainly depends on the type, size, quantity and distribution of precipitates in the grain $[5,6]$. The size and distribution of the precipitated phase of the aluminum alloy have an effect on the recrystallization of the aluminum alloy $[7,8]$. The fine precipitation phase produces age strengthening, prevents the migration of dislocations, and thus increases the strength of the alloy, which is one of the ways to improve the properties of the alloy $[9,10]$. Many researchers have studied the relationship between the size of the precipitated phase and its mechanical properties [11].

When an acoustic wave encounters an interface composed of different acoustic impedance media during propagation, scattering occurs, which depletes the energy of the acoustic wave, and the ultrasonic velocity and attenuation change with the acoustic wave energy decrease. Ultrasonic techniques have been considered a potential non-destructive evaluation (NDE) tool for the assessment of microstructural changes in materials, the measurable properties of the material when being tested by ultrasonic methods are the velocity of the sound waves passing through the material and the loss of energy or attenuation of the sound waves in the material. The aluminum alloy precipitated phase is characterized by ultrasonic techniques based on the fact that nonlinear ultrasound interacts highly sensitively 
with material microstructures such as dislocations and precipitates [12,13]. Ultrasonic velocity and attenuation measurements have been found to be very effective probes for detecting fine-scale Guinier-Preston zones (GP zones) precipitation in 8090 Al-Li alloy [14]. S Muthu Kumaran [15] found the ultrasonic velocity decreased with dissolution and coarsening of $\mathrm{S}^{\prime}$ and $\mathrm{S}^{\prime \prime}$ precipitates in $2024 \mathrm{Al}$-alloy and characterize the different phase formations and dissolutions at high temperature by ultrasonic method. Ultrasonic testing technology is emerging as a possible alternative for the evaluation of microstructural degradation of in-service components, compared to conventional microscopic and hardness testing. However, how to quickly detect the size of the $\mathrm{Al}-\mathrm{Zn}-\mathrm{Mg}-\mathrm{Cu}$ alloy precipitated phase and then characterize the mechanical properties of the alloy is still a problem to be solved.

Laser ultrasonic testing technology is a non-destructive testing technology that meets real-time detection requirements [16]. Based on the thermal bombing and ablation mechanism, the pulsed laser focuses on the surface of the sample to generate ultrasonic waves, and the microstructure of the material is characterized by measuring the characteristic changes of the ultrasonic waves. It has developed rapidly in recent years and has been used in grain size [17,18], grain size distribution [19], thickness [20], and texture [21] evaluation.

In this paper, we used laser ultrasonic detection technology to characterize 7055 aluminum alloy with different precipitated phase sizes. The ultrasonic attenuation coefficients are calculated by the amplitude attenuation method, and denoising by wavelet threshold denoising method. The effects of the precipitated phase size on ultrasonic attenuation and velocity were also studied.

\section{Experimental Materials and Methods}

\subsection{Experimental}

The experimental material is 7055 aluminum alloy sheets with a thickness of $5 \mathrm{~mm}$. The chemical composition is shown in Table 1.

Table 1. Chemical composition of 7055 aluminum alloy (wt.\%).

\begin{tabular}{ccccccccc}
\hline Chemical & Zn & Mg & Cu & Fe & Si & Ti & Zr & Al \\
\hline Content & 8.38 & 2.07 & 2.31 & 0.092 & 0.056 & 0.16 & 0.13 & Bal. \\
\hline
\end{tabular}

Heat treatment can change the microstructure and texture of the continuous casting billet and the supersaturation of the solute elements in the matrix [22,23]. The sample was placed in a heat treatment furnace for heat treatment, and after holding at $470{ }^{\circ} \mathrm{C}$ for $8 \mathrm{~h}$, the temperature was raised to $475^{\circ} \mathrm{C}$ for $16 \mathrm{~h}$, the cooling method was selected to be water-cooled, make the precipitated phase fully remelt and then aging treatment was carried out at $120^{\circ} \mathrm{C}$ for $24 \mathrm{~h}$. In this experiment, the $5 \mathrm{~mm}$ thick aluminum alloy sheets were rolled to $4 \mathrm{~mm}, 3 \mathrm{~mm}, 2 \mathrm{~mm}$ and $1 \mathrm{~mm}$, and the reduction rate was $20 \%, 40 \%, 60 \%$ and $80 \%$, respectively. The specific process parameters of the samples are shown in Table 2 . $R$ is the radius of the roll, $V$ is the rolling speed, $h_{0}$ and $h_{1}$ represent the thickness of the sample before and after rolling, $T$ is the rolling treatment.

Then the experimental samples were cut from the rolled sheets and then mechanically polished, and observed by MC80Dx optical microscopy (OM, Zeiss, Jena, Germany) and SU5000 scanning electron microscopy (SEM Hitachi, Tokyo, Japan), the polished specimens were etched with Keller's reagent $(1.5 \% \mathrm{HCl}+1 \% \mathrm{HF}+2.5 \% \mathrm{HNO} 3+95 \%$ distilled water (Vol.\%)). Subsequently, thin films (with $1 \mathrm{~mm}$ thick) were cut from the sheet center, on which discs with diameter of $3 \mathrm{~mm}$ were punched, then ground to about $100 \mu \mathrm{m}$, and then twin-jet electropolished with $70 \%$ methanol and 30\% nitric acid to prepare the thin film for transmission electron microscopy (TEM, H-800 (Hitachi, Tokyo, Japan) and Tecnai F30 (FEI, Hillsboro, OR, USA) and temperature: $-20 \sim-30^{\circ} \mathrm{C}$, potential difference: $30 \mathrm{~V}$ ). MTS 810 universal testing machine (MTS, Eden Prairie, MN, USA) was used to measure mechanical properties at room temperature with a nominal strain rate of $10^{-3} \mathrm{~s}^{-1}$. The 
software "Image J" (version:1.52v, National Institutes of Health, Image J, MD, USA) was used to analyze grain sizes and the size of the second phase.

Table 2. Specific process parameters of samples.

\begin{tabular}{|c|c|c|c|c|c|c|c|}
\hline Sample No. & $\begin{array}{l}\text { Solution } \\
\text { Treatment }\end{array}$ & $\begin{array}{c}\text { Aging } \\
\text { Treatment }\end{array}$ & $\begin{array}{c}R \\
(\mathrm{~mm})\end{array}$ & $\begin{array}{c}V \\
(\mathrm{~mm} / \mathrm{s})\end{array}$ & $T$ & $h_{0}$ & $h_{1}$ \\
\hline $7055-1$ & & & & & & 5 & 4 \\
\hline $7055-2$ & $470{ }^{\circ} \mathrm{C} / 8 \mathrm{~h}+$ & & & & & 5 & 3 \\
\hline $7055-3$ & $475^{\circ} \mathrm{C} / 16 \mathrm{~h}$ & $120^{\circ} \mathrm{C} / 24 \mathrm{~h}$ & 132 & 212 & $170^{\circ} \mathrm{C}$ & 5 & 2 \\
\hline $7055-4$ & & & & & & 5 & 1 \\
\hline
\end{tabular}

\subsection{Laser Ultrasonic Testing System}

The laser ultrasonic laboratory detection system is shown in Figure 1. The pulse laser used in the test is a Q-switched neodymium-doped yttrium aluminum garnet Laser (Q-Switched Nd: YAG Laser, Continuum, San Jose, CA, USA), the pulse width is 12 ns, the wavelength is $532 \mathrm{~nm}$, and the pulse energy is $200 \mathrm{~mJ}$. The laser ultrasound receiving system is a TWM-532 interferometer with a bandwidth of $200 \mathrm{MHz}$ and a wavelength of $532 \mathrm{~nm}$. In order to eliminate the ultrasonic signal acquisition error, each sample was measured 9 times, and each test averaged 128 times.

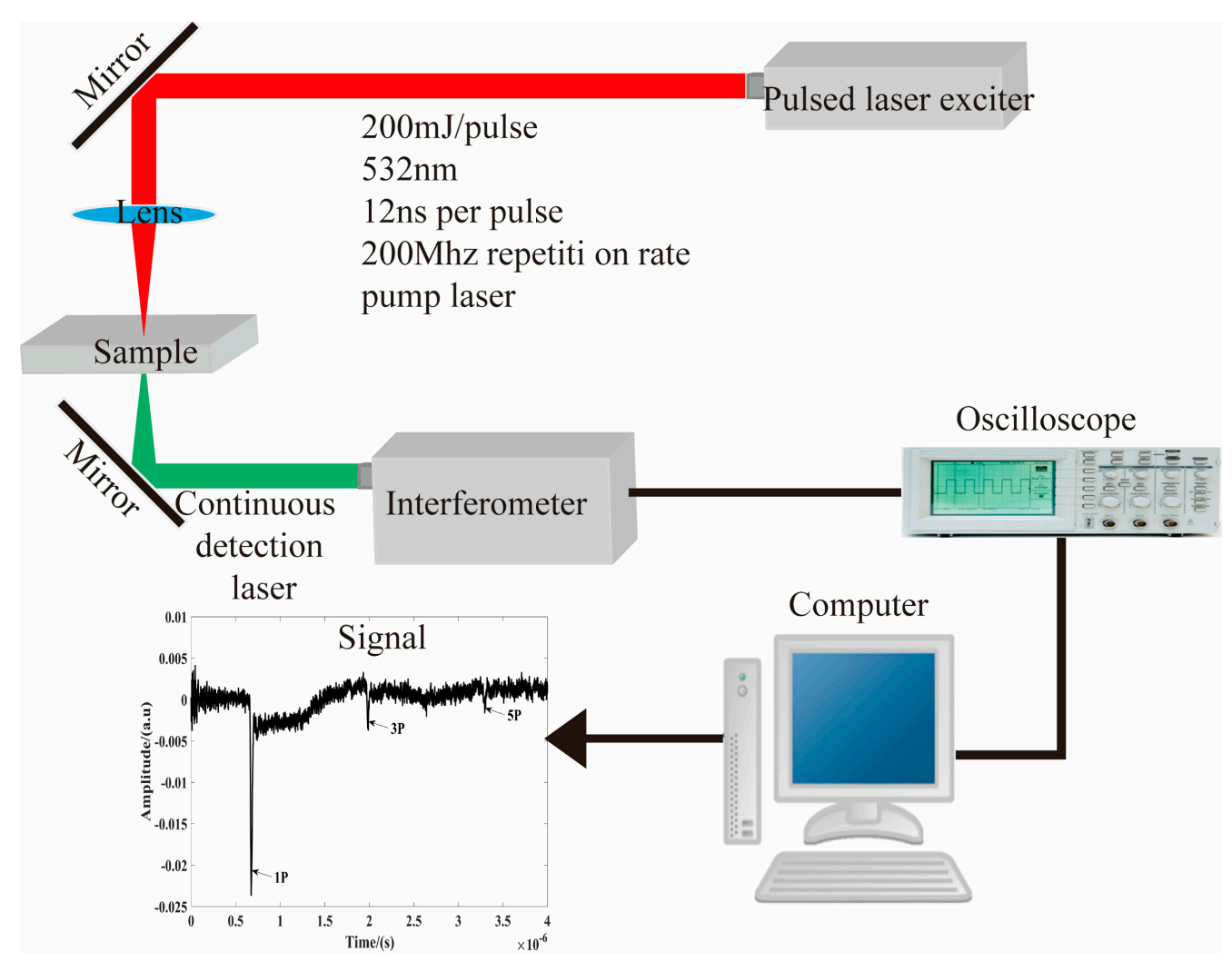

Figure 1. Laser Ultrasonic Laboratory Testing System.

\section{Results}

\subsection{Grain Size}

The microstructures of the samples measured by an optical microscope are shown in Figure 2, and the microstructures of the samples measured by SEM are shown in Figure 3. Grain size is an important indicator in the quality control of metallic materials due to its influence on the mechanical properties of these materials (fatigue, creep, yield strength, and formability) $[24,25]$. With the increase of the reduction rates, the grains are significantly 
elongated. When the reduction rate is $40 \%$, the grain shape of the sample is elongated along the rolling direction, and some grains show an irregular shape. When the reduction rate is $80 \%$, the grains of the sample are basically slender spindle-shaped. Table 3 shows the calculation results of the grain size in width.

Table 3. Mean grain size of samples.

\begin{tabular}{cccccc}
\hline Sample No. & Origin Sample & $\mathbf{7 0 5 5 - 1}$ & $\mathbf{7 0 5 5 - 2}$ & $\mathbf{7 0 5 5 - 3}$ & $\mathbf{7 0 5 5 - 4}$ \\
\hline Grain size $/(\mu \mathrm{m})$ & 53.5 & 14.9 & 11.9 & 8.1 & 7.2 \\
\hline
\end{tabular}

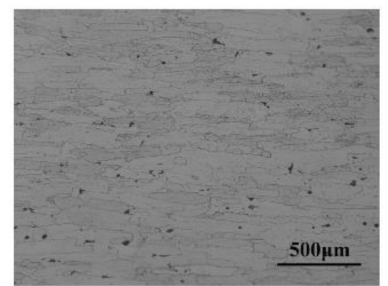

Figure 2. Microstructure of sample before rolling.

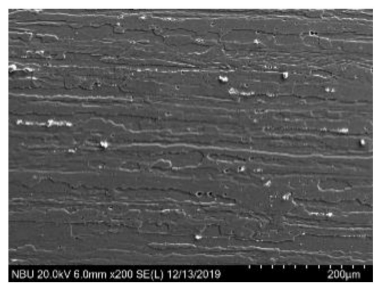

(a)

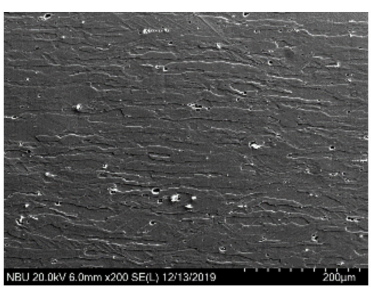

(b)

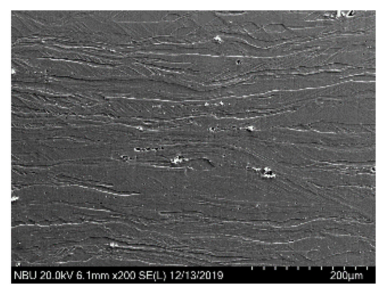

(c)

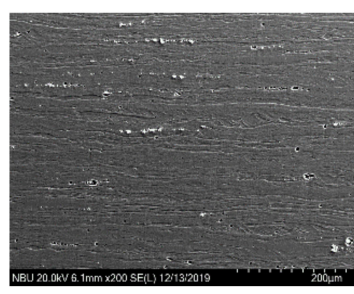

(d)

Figure 3. Microstructure measured by SEM: (a) 7055-1; (b) 7055-2; (c) 7055-3; (d) 7055-4.

\subsection{Precipitation Phase Size}

Figure 4 shows the precipitation phases of the four samples detected by TEM. The size of the precipitated phase of the sample is measured using ImageJ software. In order to reduce the error, each sample is evenly divided into 20 parts, and one precipitate phase is taken separately. The average of the secondary results is taken as the average size of the precipitated phase. Table 4 shows the calculation results of the average size of the precipitated phase.

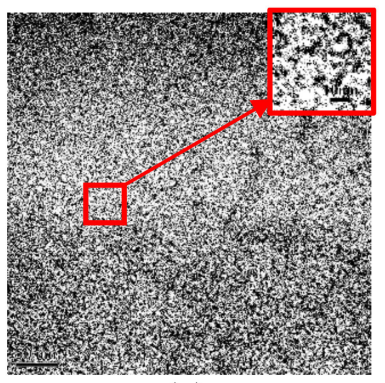

(a)

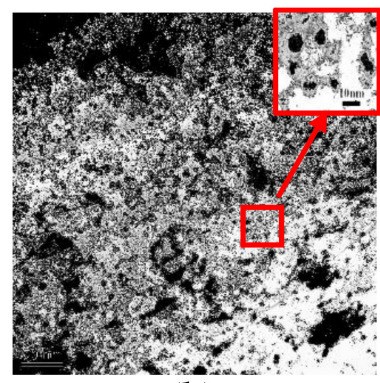

(b)

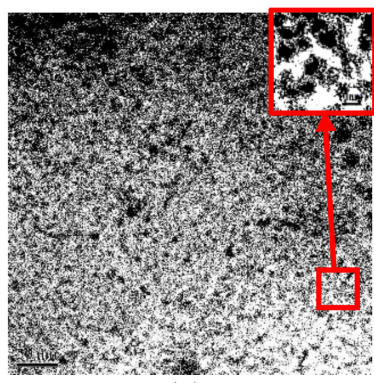

(c)

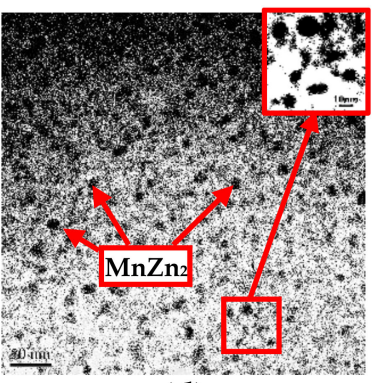

(d)

Figure 4. Precipitation measured by TEM: (a) 7055-1; (b) 7055-2; (c) 7055-3; (d) 7055-4.

Table 4. Average precipitation size of samples.

\begin{tabular}{ccccc}
\hline Sample No. & $\mathbf{7 0 5 5 - 1}$ & $\mathbf{7 0 5 5 - 2}$ & $\mathbf{7 0 5 5 - 3}$ & $\mathbf{7 0 5 5 - 4}$ \\
\hline Average size of precipitation $/(\mathrm{nm})$ & 3.9 & 5.5 & 8.9 & 10.2 \\
\hline
\end{tabular}


In 7055 aluminum alloys, $\mathrm{Zn}$ and $\mathrm{Mg}$ are the main elements of the precipitated phase $\mathrm{MgZn}_{2}[26,27]$. The shape variables of the aluminum alloy are controlled by changing the amount of reduction during the rolling process. It has been shown that as the reduction rates increases, a dynamic precipitation process [28,29] occurs during the deformation process, and at the same time, the fine grain strengthening effect of the grain refinement is gradually refined. Such a large plastic deformation also causes the precipitation size change, and more deformation defects are introduced due to the increased deformation amount (such as point defects, dislocations, and deformation), these structurally large defects will become a rapid diffusion channel of solute atoms, thereby accelerating atomic diffusion and promoting the growth of precipitated phase particles, so the size of the precipitated phase increases with the deformation increase.

Through observation, there are a large number of precipitated phase particles in the 7055 aluminum alloy after rolling deformation. When the reduction rate is small, the continuous and uniform distribution of the aluminum alloy precipitates is small and the density is high. With the increase of the reduction rates, the precipitated phase grows upward. In the sample to be tested, the average size of the precipitated phase of the sample was between $3.49 \mathrm{~nm}$ and $10.2 \mathrm{~nm}$. It is easy to know that the reduction of the rolling of the aluminum alloy sample is linear with the size of the precipitated phase, and the average size of the precipitated phase increases as the reduction rate increases.

\subsection{Mechanical Properties of Rolled Specimens with Different Reductions}

According to international standards ASTM E8, the sample stretches along the rolling direction. The mechanical properties of the samples under different reduction rates were measured and are shown in Table 5. It can be seen that as the reduction rates increase, the tensile strength and yield strength of the sample first increase to a maximum value and then slowly decrease, and the elongation of the sample decreases to a minimum value and then slowly rises. This is because the dislocation density will affect the elongation of aluminum alloy. The dislocation density increases with the increase of the deformation. When the deformation reaches $80 \%$, the dynamic recovery increases and the dislocation density begins to decrease. The conductivity of the sample increases as the amount of reduction increases.

The microstructure of the 7075 rolled sheet is mainly composed of a mixed structure composed of a deformed structure and a dynamic recrystallized structure. The tensile strength, yield strength and elongation of the samples with different reductions have a wave-like change. The strength increases as the deformation amount increases, and starts to decrease when the deformation amount reaches a certain level. The mechanical properties of the samples under different reduction rates were measured and are shown in Figure 5.

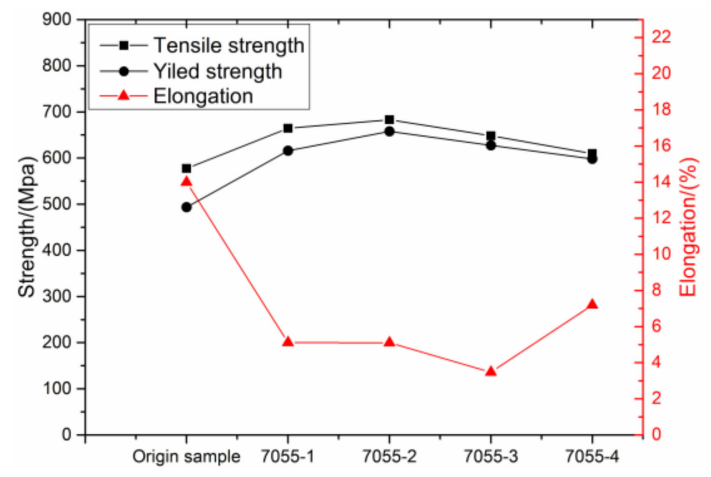

(a)

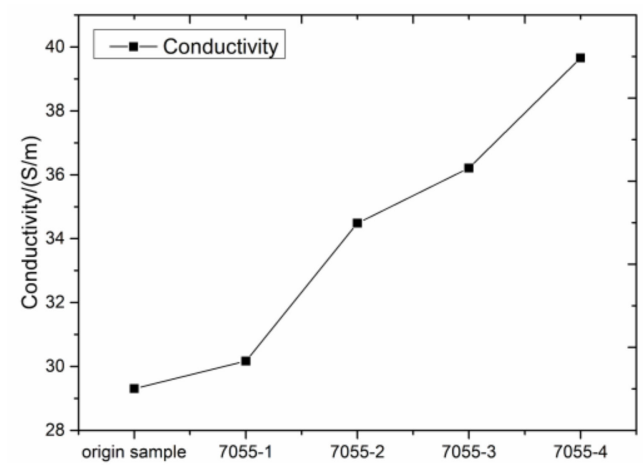

(b)

Figure 5. Mechanical properties of the samples: (a) strength and elongation; (b) conductivity. 
Table 5. Mechanical properties of samples.

\begin{tabular}{cccccc}
\hline Sample No. & Origin Sample & $\mathbf{7 0 5 5 - 1}$ & $\mathbf{7 0 5 5 - 2}$ & $\mathbf{7 0 5 5 - 3}$ & $\mathbf{7 0 5 5 - 4}$ \\
\hline Deformation/(\%) & 0 & 20 & 40 & 60 & 80 \\
Tensile strength/(MPa) & 577.6 & 664.5 & 683.3 & 648.2 & 609.6 \\
Yield strength/(MPa) & 493.4 & 616.1 & 657.8 & 627.6 & 598.1 \\
Elongation $/(\mathrm{L} / \mathrm{L} \times 100 \%)$ & 14 & 5.1 & 5.1 & 3.5 & 7.2 \\
Conductivity/(S/m) & 29.3 & 30.2 & 34.5 & 36.2 & 39.7 \\
\hline
\end{tabular}

\section{Analysis and Discussion}

\subsection{Signal Processing}

The acquisition of ultrasonic signals in laser ultrasonic detection often contains a lot of noise, which has a negative impact on the attenuation calculation of ultrasonic signals [30]. As a multi-scale expression, wavelet analysis can provide both time-domain and frequency-domain information of the signal. It has many advantages in image and signal processing wavelet analysis, as a multi-scale expression, it can provide both timedomain and frequency-domain information of the signal [31,32]. Smooth processing and wavelet threshold is useful for signal denoising. The processed signal is shown in Figure 6.
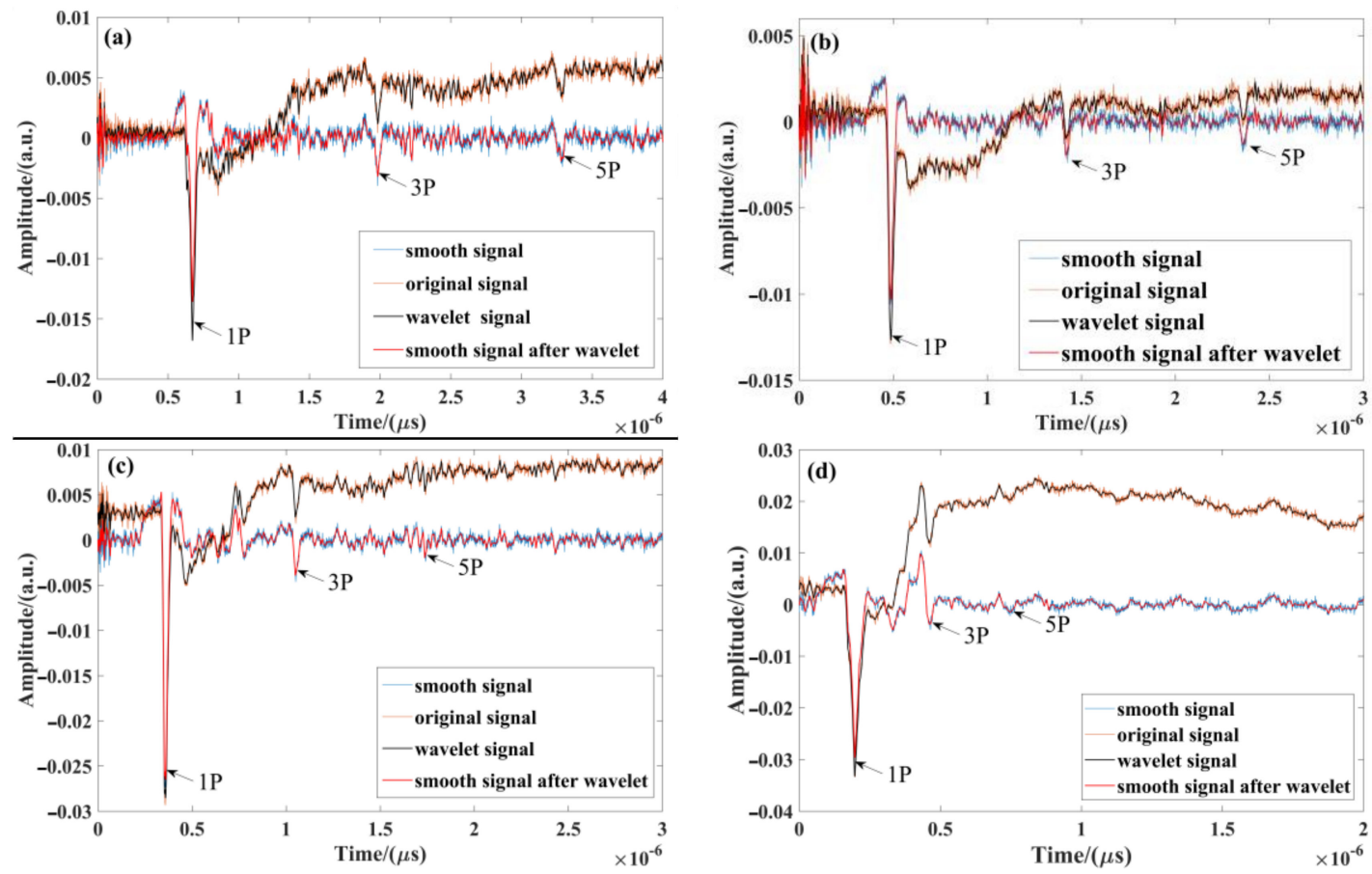

Figure 6. Ultrasonic signal of sample: (a) 7055-1; (b) 7055-2; (c) 7055-3; (d) 7055-4.

\subsection{Attenuation Coefficient}

In the process of ultrasonic propagation, when it encounters an interface composed of media with different acoustic impedances, scattered reflections will occur and the sound energy will be dispersed. The average size of the precipitated phase of the sample changed after rolling. The boundary size of the precipitation phase increases with the increment of the precipitated phase size. The attenuation coefficient is measured by the amplitude attenuation analysis method, and the amplitude (ordinate) of the first echo 1P, the second echo 3P, and the third echo 5P as shown in Figure 6 is extracted for each set of ultrasonic data. When the amplitude is selected, the corresponding peak (or trough) is selected, and the extracted amplitude data is substituted into the attenuation calculation formula [33] and the attenuation coefficient is calculated. The attenuation coefficient is taken from the same sample nine times to detect the average attenuation coefficient. 


$$
\alpha=\frac{1}{2 L} \lg \left|\frac{A_{n+1}}{A_{n}}\right|
$$

where $\alpha$ : ultrasonic attenuation

$A_{n}$ : the amplitude of the first echo 1P

$A_{n+1}$ : amplitude of the second echo 3P

$L$ : thickness of the sample

This section presents a method for calculating the ultrasonic attenuation coefficient by extracting the amplitude of the three echoes in the ultrasonic data. In Figure 6, the first echo $1 \mathrm{P}$, second echo $3 \mathrm{P}$, and third echo $5 \mathrm{P}$ are selected, and the three echoes extracted from the ultrasonic signal are subjected to Fast Fourier Transform (FFT) processing as shown by the following formula by Origin software. The ultrasonic frequency domain amplitude is shown in Figure 7.

$$
X(\omega)=\int_{-\infty}^{\infty} x(t) \exp (-j \omega t) \mathrm{d} t
$$

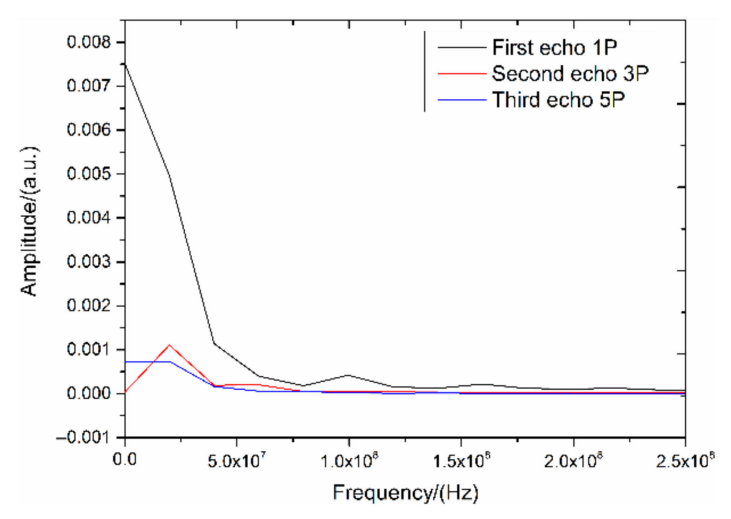

Figure 7. Ultrasonic amplitude in frequency.

The maximum amplitude of each echo is extracted and substituted into Equation (3) to calculate the ultrasonic attenuation coefficient.

$$
P=A e^{-\alpha x}
$$

where $P$ : amplitude, $\alpha$ : attenuation coefficient, $x$ : ultrasonic propagation distance.

Using the above-mentioned method for calculating the ultrasonic attenuation coeffi-

\begin{tabular}{|c|c|c|c|c|c|c|c|}
\hline \multirow{3}{*}{ Sample No. } & \multirow{3}{*}{$\begin{array}{l}\text { Average Size of } \\
\text { Precipitates/(nm) }\end{array}$} & \multicolumn{6}{|c|}{ Attenuation Coefficient/(dB/mm) } \\
\hline & & \multicolumn{2}{|c|}{$\alpha$ (Signal) } & \multicolumn{2}{|c|}{$\alpha$ (Smooth) } & \multicolumn{2}{|c|}{$\alpha(\mathrm{FFT})$} \\
\hline & & $\begin{array}{l}\text { Origin } \\
\text { Signal }\end{array}$ & $\begin{array}{c}\text { Wavelet } \\
\text { Signal }\end{array}$ & $\begin{array}{l}\text { Origin } \\
\text { Signal }\end{array}$ & $\begin{array}{c}\text { Wavelet } \\
\text { Signal }\end{array}$ & $\begin{array}{l}\text { Origin } \\
\text { Signal }\end{array}$ & $\begin{array}{c}\text { Wavelet } \\
\text { Signal }\end{array}$ \\
\hline $7055-1$ & 3.9 & 0.08544 & 0.12686 & 0.07302 & 0.11248 & 0.16421 & 0.16854 \\
\hline $7055-2$ & 5.5 & 0.13632 & 0.14883 & 0.10881 & 0.11666 & 0.49057 & 0.35236 \\
\hline $7055-3$ & 8.9 & 0.19621 & 0.14812 & 0.18319 & 0.13707 & 0.42687 & 0.42028 \\
\hline $7055-4$ & 10.2 & 0.33388 & 0.17384 & 0.39799 & 0.14671 & 0.74207 & 1.06924 \\
\hline
\end{tabular}
cient based on the frequency domain amplitude and the results are shown in Table 6.

Table 6. Attenuation coefficient of ultrasonic waves.

It can be seen from Tables 3 and 6 that with the increase of the reduction rates, the grain size decreases slightly, but the attenuation coefficient of the ultrasonic wave increases obviously. Studies have shown that the attenuation coefficient increases with the increment of grain size $[16,17,24]$. Furthermore, the precipitated phase size increased significantly, so 
the increase in the precipitated phase size of the sample is the main influencing factor for the change of ultrasonic attenuation. The relationship between the precipitation size and the ultrasonic attenuation coefficient is shown in Figure 8.

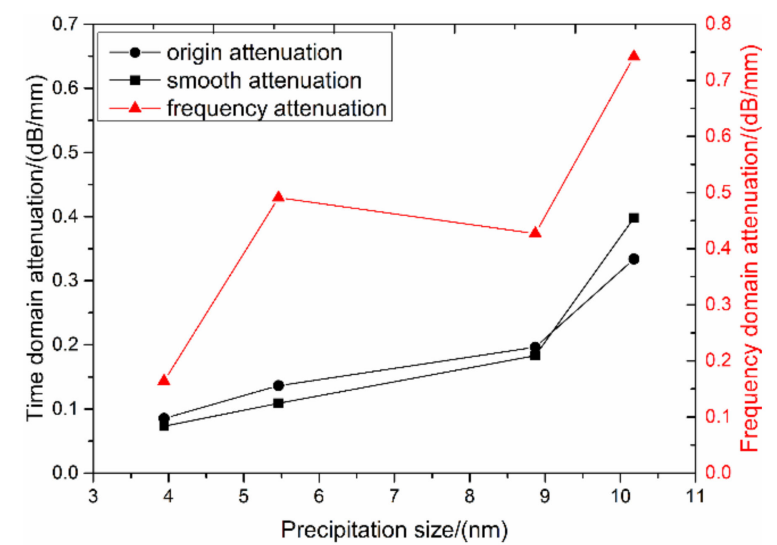

(a)

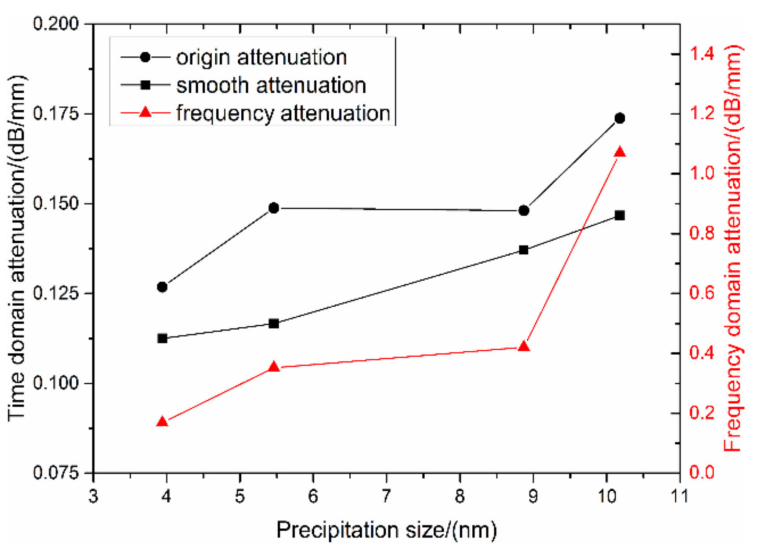

(b)

Figure 8. Relationship between the precipitation size and the ultrasonic attenuation coefficient: (a) attenuation coefficient calculated by origin signal; (b) attenuation coefficient calculated by wavelet signal.

\subsection{Ultrasonic Velocity}

Based on the above analysis, it can be understood that the ultrasonic attenuation coefficient tends to increase with the increase in the size of the precipitated phase. The ultrasonic velocities of samples are shown in Table 7. The effects of the precipitated phase size on ultrasonic velocity are shown in Figure 9.

Table 7. Ultrasonic velocity.

\begin{tabular}{ccccc}
\hline Sample No. & $\mathbf{7 0 5 5 - 1}$ & $\mathbf{7 0 5 5 - 2}$ & $\mathbf{7 0 5 5 - 3}$ & $\mathbf{7 0 5 5 - 4}$ \\
\hline Average size of precipitates/(nm) & 3.9 & 5.5 & 8.9 & 10.2 \\
Ultrasonic velocity/(m/s) & 6116.976 & 6172.192 & 6154.264 & 6362.386 \\
\hline
\end{tabular}

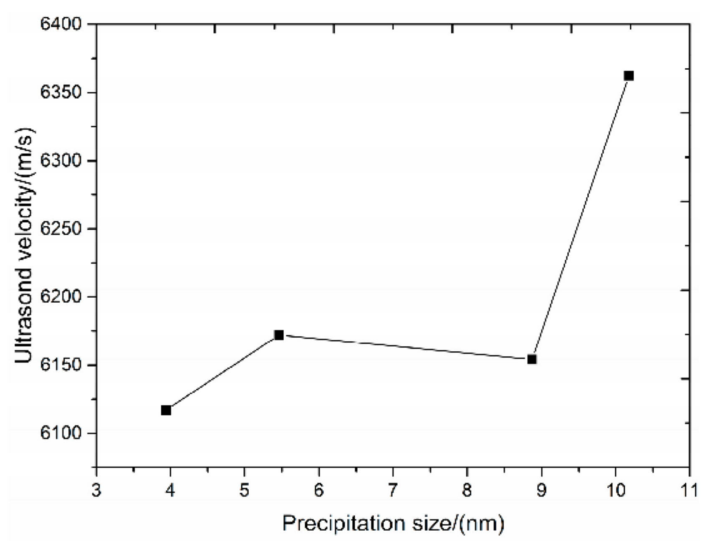

Figure 9. The precipitation size and the ultrasonic velocity graph of four samples.

It can be seen from Figure 9 that the ultrasound velocity also shows obvious correspondence with the average size of the precipitation phase. In laser ultrasonic nondestructive testing, the ultrasonic velocity depends on the material properties, such as the coefficient of elasticity of single crystals and the anisotropy of polycrystals materials. The ultrasound velocity is suitable for characterizing the relative change of the microstructure of the material. 
In the rolling process, with the increase of the deformation, dynamic recovery will appear in the sample, the sub-crystals will be formed and will affect the elongation of the sample. This shows that the ultrasonic velocity change is more suitable for the evaluation of elongation.

\subsection{Discussion}

When ultrasonic waves propagate in metal materials, scattering attenuation and absorption attenuation occur. Studies have shown that absorption attenuation is independent of the average size of the precipitation phase. When an acoustic wave encounters an interface composed of different acoustic impedance media during propagation, scattering occurs, which depletes the energy of the acoustic wave. The scattered acoustic wave propagates along the complex path in the medium and eventually becomes thermal energy.

The longitudinal wave attenuation coefficient obtained by four different calculation methods is used to characterize the microstructure of aluminum alloy under different reduction conditions, and the wavelet threshold is used to signal denoising. The longitudinal wave attenuation coefficient measured by laser ultrasonic method was compared with the size of the precipitated phase observed by transmission electron microscopy. Due to the presence of a large number of precipitated phases in the 7055 aluminum alloy, the scattering of the ultrasonic waves is enhanced, resulting in an increased attenuation coefficient based on the longitudinal wave measurement. In the sample to be tested, the average size of the precipitated phase of the sample was between $3.49 \mathrm{~nm}$ and $10.2 \mathrm{~nm}$. With the increase of the reduction rates, the size of the precipitated phase increases. With the increase of the precipitation phase, the average size of the precipitated phase $\mathrm{MnZn} \mathrm{n}_{2}$ increases. The boundary size of the precipitation phase increases with the average size of the precipitated phase increase. The results of ultrasonic velocity show that the velocity value also has obvious correspondence with the average size of the precipitation phase.

By establishing the relationship between the ultrasonic attenuation coefficient, ultrasonic velocity and the size of the precipitation phase, it can be found that the attenuation coefficient and the ultrasonic velocity increase with the increment of the precipitated phase size, but the change of the ultrasonic velocity depends on the change of microstructure composition, therefore, the ultrasonic attenuation coefficient is more suitable for characterizing the size of the precipitation phase. Ultrasound velocity is suitable for characterizing the recrystallization and size of materials. It is indicated that the laser ultrasonic method can be used to characterize the size of the precipitated phase of the 7055 aluminum alloy.

\section{Conclusions}

In this paper, a laser-ultrasonic approach based on the precipitated phase size dependence of the attenuation coefficient of an ultrasonic wave for the measurement of precipitated phase size in 7055 aluminum alloy was proposed. The size of the precipitated phase of 7055 aluminum alloy was observed by TEM, and the 7055 aluminum alloy with four different precipitated phase sizes was detected by laser ultrasonic nondestructive testing technology. The coefficients of ultrasound measured by laser ultrasonic test were calculated in the time domain and frequency domain, respectively. The results show that the size of 7055 aluminum alloy precipitates has a certain influence on ultrasonic velocity and ultrasonic attenuation coefficient, which provides a new method for the rapid detection of aluminum alloy precipitate size. At the same time, combined with the microscopic structure and mechanical property model, the on-line mechanical property detection of aluminum alloy becomes possible.

Author Contributions: Conceptualization, Z.Z., H.P. and A.Y.; methodology, Z.Z. and A.Y.; formal analysis, Z.Z. and H.P.; investigation, Z.Z., H.P. and A.Y.; writing-original draft preparation, Z.Z.; writing-review and editing, Y.X., X.S. (Xueyong Song), J.Z., Y.W., X.S. (Xuedao Shu) and A.Y.; visualization, Z.Z., H.P., Y.X., X.S. (Xueyong Song) and A.Y.; supervision, A.Y. and X.S. (Xuedao $\mathrm{Shu}$ ); project administration, A.Y. All authors have read and agreed to the published version of the manuscript. 
Funding: This work was supported by National Natural Science Foundation of China (NSFC) (51805279); Natural Science Foundation of Zhejiang Province (LY21E050004, LQ19E010003); Ningbo Natural Science Foundation (No. 202003N4082); Projects in Science and Technique Plans of Ningbo City (2020Z110).

Data Availability Statement: Data is contained within the article.

Conflicts of Interest: The authors declare no conflict of interest.

Abbreviations
$\begin{array}{ll}\text { The following abbreviations are used in this manuscript: } \\ \text { TEM } & \text { Transmission Electron Microscope } \\ \text { SEM } & \text { Scanning Electron Microscope } \\ \text { Q-Switched Nd: YAG Laser } & \text { Q-switched neodymium-doped yttrium aluminum garnet Laser } \\ \text { FFT } & \text { Fast Fourier Transform }\end{array}$

\section{References}

1. D'Scotto, D.S.; Gaies, J.; Golumbfskie, W.; Taheri, M.L. Direct measurement of the effect of cold rolling on $\beta$ phase precipitation kinetics in 5xxx series aluminum alloys. Acta. Mater. 2017, 123, 264-271.

2. Thronsen, E.; Marioara, C.D.; Sunde, J.K.; Minakuchi, K.; Katsumi, T.; Erga, I.; Andersen, S.J.; Friis, J.; Marthinsen, K.; Matsuda, K. The effect of heavy deformation on the precipitation in an Al-1.3Cu-1.0Mg-0.4Si wt.\% alloy. Mater. Des. 2020, 186. [CrossRef]

3. Jia, Y.W.; Wang, S.C.; Shu, D. Grain size prediction and investigation of 7055 aluminum alloy inoculated by Al-5Ti-1B master alloy. J. Alloys. Compd. 2019, 821. [CrossRef]

4. Kaibyshev, R.; Sakai, T.; Musin, F.; Nikulin, I.; Miura, H. Superplastic behavior of a 7055 aluminum alloy. Scripta Materialia 2001, 45, 1373-1380. [CrossRef]

5. Morris, J.G.; Liu, W.C. Al alloys: The influence of concurrent precipitation on recrystallization behavior, kinetics, and texture. JOM 2005, 57, 44-47. [CrossRef]

6. Ralston, K.D.; Birbilis, N.; Weyland, M.; Hutchinson, C.R. Al alloy: The effect of precipitate size on the yield strength-pitting corrosion correlation in Al-Cu-Mg alloys. Acta. Mater. 2010, 58, 5941-5948. [CrossRef]

7. Zhang, J.X.; Sun, H.Y.; Li, J.; Liu, W.C. Effect of precipitation state on recrystallization texture of continuous cast AA 2037 aluminum alloy. Mater. Sci. Eng. A 2019, 754, 491-501. [CrossRef]

8. Zuo, J.R.; Hou, L.G.; Shu, X.D.; Peng, W.F.; Yin, A.M.; Zhang, J.S. Grain Refinement Assisted by Deformation Enhanced Precipitates through Thermomechanical Treatment of AA7055 Al Alloy. Metals 2020, 10, 594. [CrossRef]

9. Zuo, J.R.; Hou, L.G.; Shi, J.T.; Cui, H.; Zhuang, L.Z.; Zhang, J.S. The mechanism of grain refinement and plasticity enhancement by an improved thermomechanical treatment of $7055 \mathrm{Al}$ alloy. Mater. Sci. Eng. A 2017, 702, 42-52. [CrossRef]

10. Marchese, G.; Aversa, A.; Lorusso, M.; Manfredi, D.; Calignano, F.; Lombardi, M.; Biamino, S.; Pavese, M. Development and Characterisation of Aluminium Matrix Nanocomposites $\mathrm{AlSi}_{10} \mathrm{Mg} / \mathrm{MgAl}_{2} \mathrm{O}_{4}$ by Laser Powder Bed Fusion. Metals $2018,8,175$. [CrossRef]

11. Karlik, M.; Vronka, M.; Hausild, P.; Hajek, M. Influence of cold rolling on the precipitation in an Al-Mn-Zr alloy. Mech. Time-Depend. Mat. 2015, 85, 361-366.

12. Kim, J.; Jhang, K.Y.; Kim, C. Dependence of nonlinear ultrasonic characteristic on second-phase precipitation in heat-treated Al 6061-T6 alloy. Ultrasonics 2018, 82, 84-90. [CrossRef]

13. Murthy, G.V.S.; Patel, D.; Sahoo, K.L.A. study of Precipitation behaviour of A356 alloy using ultrasonic velocity measurements. Insight 2016, 58, 367-372. [CrossRef]

14. Kumaran, S.M.; Priyadharsini, N.; Rajendran, V.; Jayakumar, T.; Palanichamy, P.; Shankar, P.; Raj, B. In situ high temperature ultrasonic evaluation for on-line characterisation of fine scale precipitation reactions in $8090 \mathrm{Al}-\mathrm{Li}$ alloy. Mat. Sci. Eng. A-Struct. 2006, 435, 29-39. [CrossRef]

15. Kumaran, S.M. Identification of high temperature precipitation reactions in $2024 \mathrm{Al}-\mathrm{Cu}-\mathrm{Mg}$ alloy through ultrasonic parameters. J. Alloy. Compd. 2012, 539, 139-183.

16. Dong, F.; Wang, X.C.; Yang, Q.; Yin, A.M.; Xu, X.D. Directional dependence of aluminum grain size measurement by laserultrasonic technique. Mater. Charact. 2017, 129, 114-120. [CrossRef]

17. Zhang, Y.J.; Wang, X.C.; Yang, Q.; Dong, F.; Du, X.Z.; Yin, A.M. Characterization of mean grain size of interstitial-free steel based on laser ultrasonic. J. Mate. Sci. 2018, 53, 8510-8522. [CrossRef]

18. Zhan, Y.; Zhang, E.D.; Ge, Y.M.; Liu, C.S. Residual Stress in Laser Welding of TC4 Titanium Alloy Based on Ultrasonic laser Technology. Appl. Sci. 2018, 8, 1997. [CrossRef]

19. Bai, X.; Zhao, Y.; Ma, J.; Liu, Y.X.; Wang, Q.W. Grain-Size Distribution Effects on the Attenuation of Laser-Generated Ultrasound in $\alpha$-Titanium Alloy. Materials 2019, 12, 102. [CrossRef]

20. Levesque, D.; Kruger, S.E.; Lamouche, G.; Kolarik, R.; Jeskey, G.; Choquet, M.; Monchalin, J.P. Thickness and grain size monitoring in seamless tube-making process using laser ultrasonics. NDT E. Int. 2006, 39, 622-626. [CrossRef] 
21. Yin, A.M.; Wang, X.C.; Glorieux, C.; Yang, Q.; Dong, F.; He, F.; Wang, Y.L.; Sermeus, J.; Van der Donck, T.; Shu, X.D. Texture in steel plates revealed by laser ultrasonic surface acoustic waves velocity dispersion analysis. Ultrasonics 2017, 78, 30-39. [CrossRef]

22. Deschamps, A.; De Geuser, F.; Horita, Z.; Lee, S.; Renou, G. Precipitation kinetics in a severely plastically deformed 7075 aluminium alloy. Acta. Mater. 2014, 66, 105-117. [CrossRef]

23. Liu, W.C.; Li, Z.; Man, C.S.; Raabe, D.; Morris, J.G. Effect of precipitation on rolling texture evolution in continuous cast AA 3105 aluminum alloy. Mater. Sci. Eng. A 2006, 434, 105-113. [CrossRef]

24. Chen, X.; Wu, G.H.; Chen, H.; Zhou, Z.G. A multi-parameter ultrasonic evaluation of mean grain size using optimization. NDT E. Int. 2019, 106, 10-17. [CrossRef]

25. Li, R.G.; Xin, R.L.; Liu, Q.; Chapuis, A.; Liu, S.F.; Fu, G.Y.; Zong, L. Effect of grain size, texture and density of precipitates on the hardnessand tensile yield stress of Mg-14Gd-0.5Zr alloys. Mater. Des. 2017, 114, 450-458. [CrossRef]

26. Zhang, J.S.; Wu, G.H.; Zhang, L.; Zhang, X.L.; Shi, C.C.; Sun, J.W. Effect of Zn on precipitation evolution and mechanical properties of a high strength cast Al-Li-Cu alloy. Mater. Charact. 2020, 160. [CrossRef]

27. Chen, Y.X.; Yang, Y.Q.; Feng, Z.Q.; Huang, B.; Luo, X. Surface gradient nanostructures in high speed machined 7055aluminum alloy. J. Alloy. Compd. 2017, 726. [CrossRef]

28. Naimi, A.; Yousfi, H.; Trari, M. Influence of cold rolling degree and ageing treatments on the precipitation hardening of 2024 and 7075 alloys. Mech. Time-Depend. Mat. 2013, 17, 285-296. [CrossRef]

29. Zuo, J.; Hou, L.; Shu, X.; Peng, W.; Yin, A.; Zhang, J. Effect of Deformation on Precipitation and the Microstructure Evolution during Multistep Thermomechanical Processing of Al-Zn-Mg-Cu Alloy. Metals 2020, 10, 1409. [CrossRef]

30. Zhang, D.; Zhao, H.B.; Yang, J.K. Signal denoising of double-beam and double-scattering laser doppler velocimetry based on wavelet layering. Optik 2020, 202. [CrossRef]

31. Wang, E.D.; Jiang, P.; Li, X.P.; Cao, H. Infrared stripe correction algorithm based on wavelet decomposition and total variationguided filtering. J. Eur. Opt. Soc.-Rapid 2019, 16, 13-21. [CrossRef]

32. Zhang, J.H.; Zhu, Q.; Zhang, J.R.; Song, L.; Wang, J.L. A novel algorithm for threshold image denoising based on wavelet construction. Cluster. Comput. 2019, 22, 12443-12450.

33. Sundin, S.; Artymowicz, D. Direct measurements of grain size in low-carbon steels using the laser ultrasonic technique. Metall. Mater. Trans. A 2019, 16, 13-21. [CrossRef] 